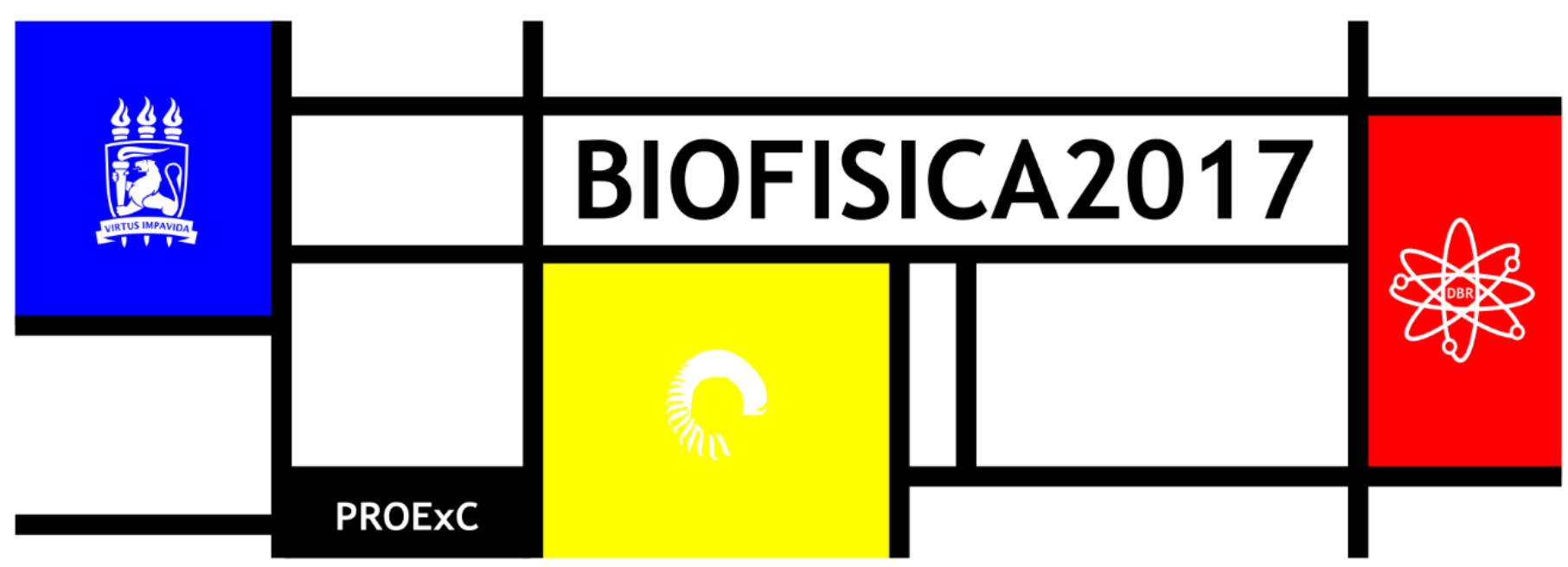

\title{
O NANOPORO PROTEICO UNITÁRIO DA a-HEMOLISINA DETECTA POLIVINILÁLCOOL?
}

\author{
Lícya Samara da Silva Xavier ${ }^{1 *}$, Cláudio Gabriel Rodrigues ${ }^{1}$, Juliana Pereira de Aguiar ${ }^{1}$ \\ ${ }^{1}$ Laboratório de Biofísica das Membranas e Células-tronco Dr. Oleg Krasilnikov, UFPE \\ *licya.samara@ufpe.br
}

\section{INTRODUÇÃO}

Os polímeros são macromoléculas constituídas por variedades estruturais repetitivas (monômeros), sendo que normalmente a unidade que se repete é de baixo peso molecular. Eles podem ser orgânicos ou inorgânicos, sintéticos ou naturais e têm sido cada vez mais aplicados em diversas áreas, a depender de suas propriedades: resistência mecânica, térmica e elétrica; estabilidade química, permeabilidade a gases, dentre outras (MANRICH, 2005). Essas propriedades são determinadas pela composição do polímero (natureza dos monômeros), massa molecular, grau de polimerização e linearidade da cadeia polimérica (MANO, E. B. Et al., 2004; IKEDA S. et al., 2012). Tendo em vista a necessidade de conhecer a estrutura dessas macromoléculas para sua adequada utilização, diferentes métodos analíticos são empregados com a finalidade de mensurar sua massa molecular. Nesse contexto, o biossensoriamento estocástico via nanoporo proteico individual aparece como um método alternativo de análise de massa. Essa técnica se baseia na observação de eventos de ligação entre as moléculas individuais de analitos e um único receptor. Esses eventos são identificados por um bloqueio característico na corrente iônica que flui através do nanoporo. A denominação "estocástico" é atribuída em relação à série temporal aleatória de flutuações discretas registradas (AGUIAR, J. P. et al., 2015). Por ser um dos mais bem caracterizados, o nanoporo utilizado nesse trabalho é formado pela a-Hemolisina ( $\mathrm{a}-\mathrm{HL}$ ) (Fig. $1 \mathrm{~A}$ e 1B), uma toxina liberada pela bactéria Staphylococcus aureus. Naturalmente, essa toxina forma poros nas membranas celulares permitindo o extravasamento dos componentes intracelulares. Cada nanoporo é composto por sete subunidades, que se oligomerizam gerando uma estrutura dividida em três regiões: troncular, anelar e copal (Fig, $1 \mathrm{~A})$. A região copal com entrada de maior diâmetro $(\sim 4,6 \mathrm{~nm})$ do poro direciona-se para o meio extracelular, enquanto que a entrada menor $(\sim 2 \mathrm{~nm})$ encontra-se voltada para o meio intracelular. Além disso, o nanoporo possui uma região de constrição de $\sim 1,4 \mathrm{~nm}$ de diâmetro (Fig.1B). Este valor de diâmetro é semelhante à dimensão da maioria dos polímeros, portanto, isto é uma das caraterísticas que propicia a utilização da $\alpha$-hemolisina como ferramenta de detecção e caracterização de diversos tipos de moléculas (DNA, RNA, proteínas, polietilenoglicol, etc...) em meio aquoso. 0 biossensoriamento através do nanoporo da $\alpha-H L$ já se mostrou eficiente para a análise da interação e da massa do polietilenoglicol (PEG) (ROBERTSON et al., 2007; RODRIGUES et al., 2008;). A escolha do álcool polivinílico (PVA) (Fig. 1C) como objeto de estudo se deve principalmente à sua aplicação como estabilizante de emulsões na preparação de medicamentos líquidos, como agente de revestimento em nanocarreadores e agentes embólicos (Fig. 1D). O PVA é um homopolímero sintético, solúvel em água, altamente hidrofílico, biodegradável e biocompatível (MANO, E. B. Et al., 2004). Por ser uma substância bioinerte, esse polímero tem grande aplicação como sistema de liberação de fármacos (AZEVEDO, 2002). Neste trabalho analisamos o transporte e a interação do PVA com o nanoporo da $\alpha$-hemolisina objetivando a detecção desse polímero.
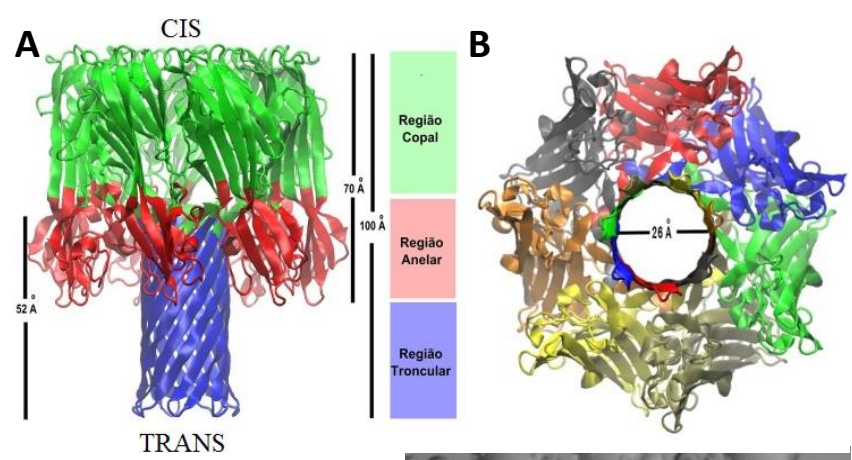

C
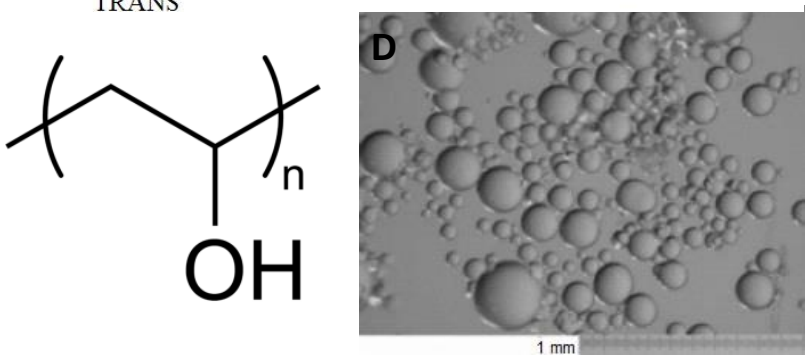

Figura 1. Modelo do nanoporo da $\alpha$-hemolisina. (A) Visão lateral com cada domínio representado em três cores. Adicionalmente indicou-se a entrada cis e trans. A coluna empilhada e as barras verticais representam a dimensão de cada um dos domínios. (B) Visão superficial com cada uma das setes subunidades representada por uma cor. A barra hisão superficial com cada uma das setes subunidades representada por uma cor. A barra horizontal representam o diâmetro da região de constrição. (C) Representação quimica como agente embólico. (Fonte: AGUIAR, J. P. et al, 2015; MENDES et al., 2005). 


\section{MATERIAIS E MÉTODOS}

Todas as bicamadas lipídicas planas livres de solvente foram confeccionadas conforme as técnicas convencionais de construção de membranas (MONTAL \& MUELLER, 1972). Esta técnica consiste basicamente na formação de uma bicamada lipídica por aposição de dois filmes monomoleculares de lipídeo sintético, num orifício de uma partição de Teflon ${ }^{\circledR}$ (Politetrafluoretileno) que separa dois compartimentos de uma câmara experimental também de Teflon ${ }^{\circledR}$, contendo soluções aquosas (Fig. 2A). Foram adicionados em cada hemicâmara 10-20 $\mu \mathrm{l}$ de uma solução de diftanoil glicerofosfocolina $2 \%(\mathrm{p} / \mathrm{v})$ em hexano. Decorridos aproximadamente 10 minutos, com a evaporação do hexano, ocorreu à formação espontânea dos filmes lipídicos monomoleculares na superfície da solução aquosa de cada compartimento. Posteriormente o nível do líquido do compartimento "Trans" foi elevado por adição de mais solução, formando a primeira monocamada. Este mesmo procedimento foi realizado no compartimento oposto para a formação da bicamada (Figura 2B). A formação da membrana foi monitorada usando lupa binocular e pelo aumento nos valores de corrente capacitiva basal (figura 2C). Após a construção da bicamada lipídica realizou-se a incorporação de um único nanoporo pela adição da $\alpha$-hemolisina na solução banhante do lado "Cis" da membrana. Posteriormente, adicionou-se o PVA ao compartimento "Trans" da câmara experimental e registrou-se a corrente iônica fluente através do nanoporo. Todos os experimentos foram realizados em condições de fixação de voltagem $( \pm 200 \mathrm{mV}, \triangle=20 \mathrm{mV})$, solução $(\mathrm{KCl} 4 \mathrm{M}$, Tris $5 \mathrm{mM}, \mathrm{pH} \mathrm{7,5)} \mathrm{e} 23 \pm 2{ }^{\circ} \mathrm{C}$. Um condutivímetro (Radiometer Analytical, CDM230) foi utilizado na determinação da condutividade de todas as soluções utilizadas nos experimentos.

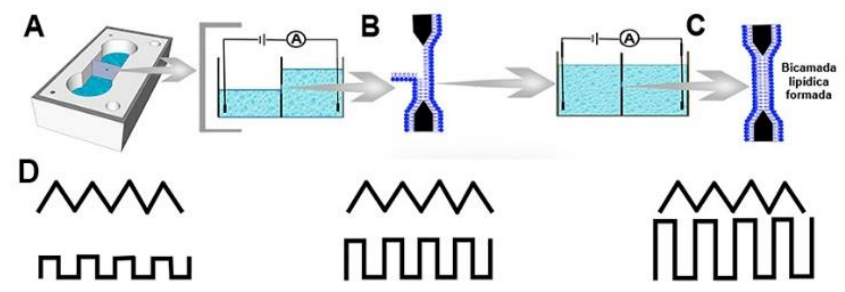

Figura 2. Esquema representativo da formação da bicamada lipídica. A) Câmara experimental. B) Montagem de uma monocamada lipídica. C) Construção da bicamada lipídica. D) Monitoramento elétrico da construção da bicamada lipídica. A onda triangular representa o perfil de potencial aplicado e a onda quadrada, o aumento da corrente capacitiva. (Fonte: AGUIAR, J. P. et al, 2015)

Em todos os experimentos o sistema utilizado para aplicação do potencial transmembrana, monitoração e aquisição dos registros era formado por um gerador de funções (Hewlett Packard, modelo 3310B), um filtro Butterworth (Frequency devices, modelo 902), um amplificador de patch clamp (Axonpatch 200B) e uma placa conversora analógico-digital (Digidata 1440) acoplada a um microcomputador IBM PC, executando o Programa PClamp 10 (Axon Instruments).

\section{RESULTADOS E DISCUSSÃO}

A condutância do nanoporo formado pela $\alpha-H L$ é um parâmetro importante na sua utilização como elemento de detecção. Esse parâmetro é influenciado pela condutividade da solução banhante utilizada. Preliminarmente determinou-se o valor de condutividade da solução de $\mathrm{KCl} 4 \mathrm{M}: 357,7 \pm 0,680 \mathrm{mS} / \mathrm{cm}(\mathrm{n}=3)$. A solução padrão de $\mathrm{KCl} 4 \mathrm{M}$, aumenta qualitativamente a sensibilidade do nanoporo da a-hemolisina (ROBERTSON, et al, 2007; RODRIGUES et al, 2008). Na figura $3^{\mathrm{a}}$, cada salto discreto na corrente representa a incorporação na bicamada lipídica de um nanoporo da ahemolisina. Nota-se claramente que os saltos apresentam praticamente a mesma amplitude de corrente. Na figura 3B encontra-se o histograma de condutância do nanoporo da a-HL em $\mathrm{KCl} 4 \mathrm{M}$, com valor médio de $3,812 \pm 0,02 \mathrm{nS}(\mathrm{n}=161)$.
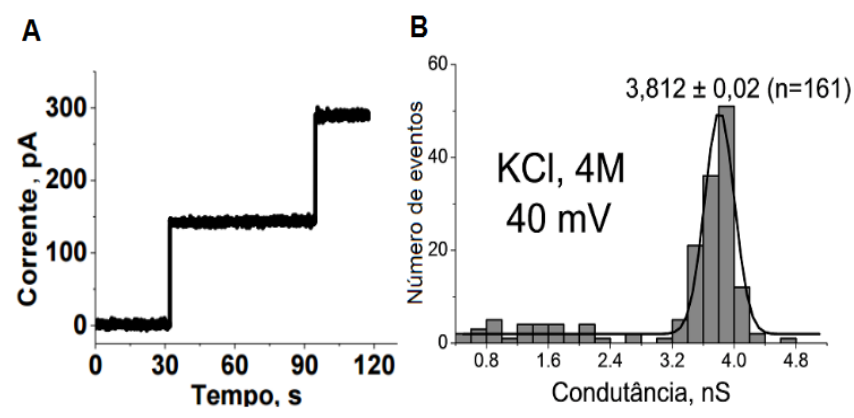

Figura 3. (A) Registro típico da corrente iônica através do nanoporo da a-Hemolisina na solução de $\mathrm{KCl} 4 \mathrm{M}$. (B) Histograma de condutância do nanoporo a_hemolisina na solução de $\mathrm{KCl} 4 \mathrm{M}$. Potencial transmembrana $=40 \mathrm{mV}$.

Posteriormente investigou-se a dependência da condutância do nanoporo da a-HL em função do potencial transmembrana, na ausência e na presença do PVA na concentração de $0,1 \mu \mathrm{M}$. Os resultados são mostrados na Figura 4 . Na presença de PVA há uma diminuição em aproximadamente $45 \%$ dos valores de condutância quando comparado ao controle, apresentando-se mais proeminente, a partir do potencial de $100 \mathrm{mV}$.

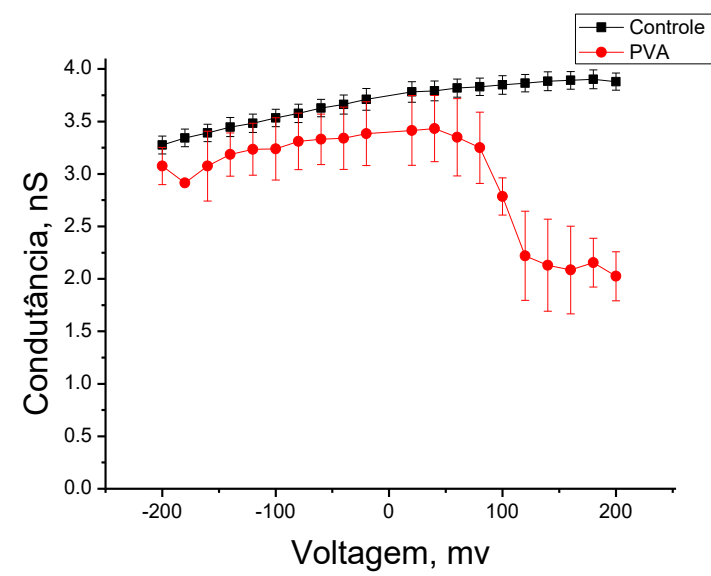

Figura 4. Efeito do PVA na condutância do nanoporo da a-hemolisina. No potencial de $100 \mathrm{mV}$ o PVA reduz a condutância em aproximadamente $45 \%$.

Nessas condições o nanoporo formado pela $\alpha-\mathrm{HL}$ incorporado em bicamada lipídica plana teve a capacidade de detectar as moléculas de PVA polidisperso de peso molecular de 30-70KDa, como pode ser observado na Figura 5. A detecção ocorre pela indução de eventos de bloqueios, ou seja, a redução da corrente iônica, caracterizada por amplitude e tempo de permanência, quando o nanoporo é banhado por solução de elevada concentração $(\mathrm{KCl} 4 \mathrm{M})$. Cada bloqueio deve-se à entrada de uma única molécula de PVA no lume aquoso do nanoporo (BAAKEN, ET AL, 2015). A amplitude e a duração dos bloqueios são característicos do tipo de analito presente, enquanto que a frequência depende da concentração, como pode ser visto nos registros típicos de corrente da interação do PVA na concentração de 0,1 nM e na concentração de $100 \mathrm{nM}$ (Fig. 5A e B). 

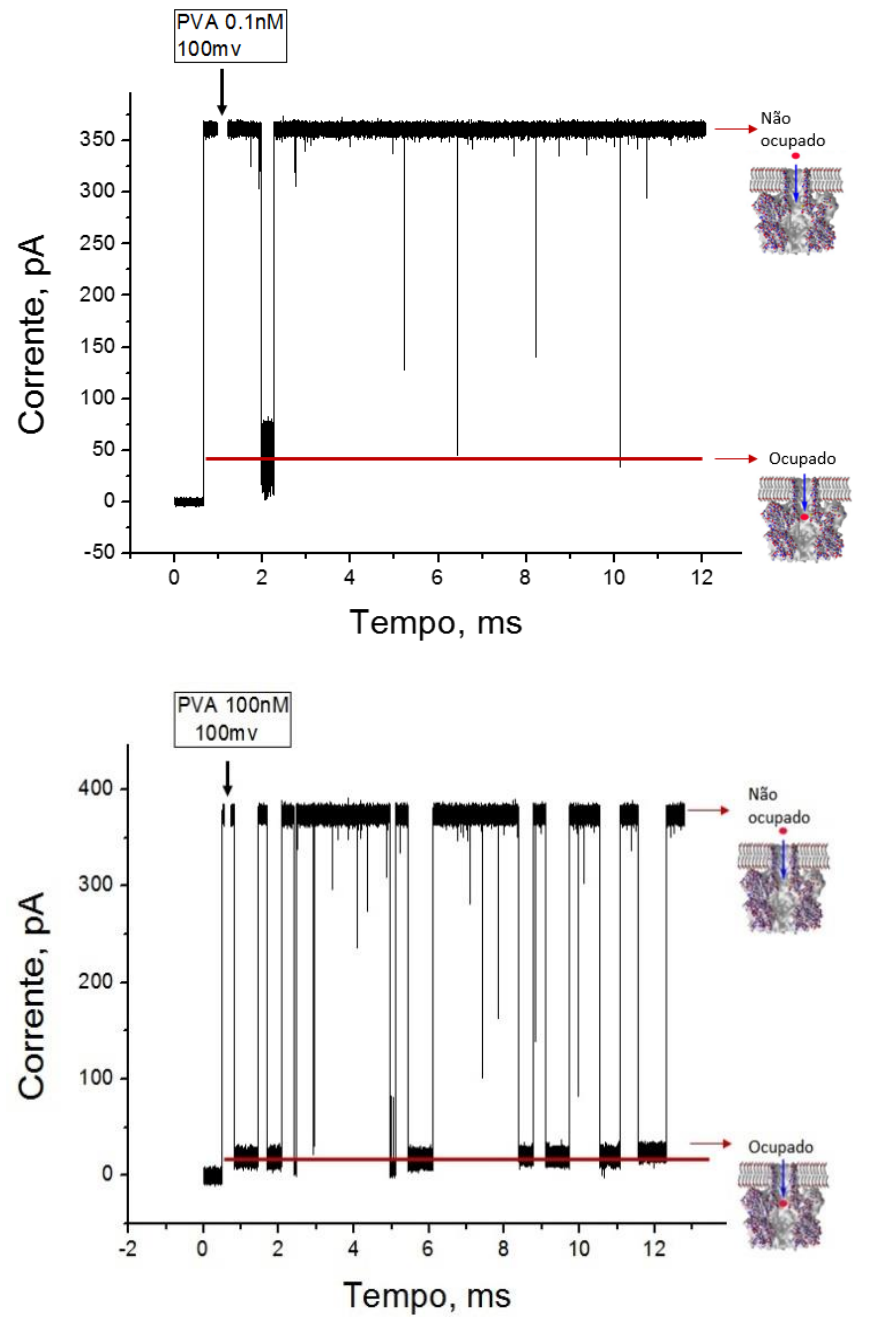

Figura 5. Registro típico da corrente iônica através do nanoporo da a-hemolisina na solução de $\mathrm{KCl} 4 \mathrm{M}, \mathrm{pH}$ 7,5 e na presença de 0,1 nM (A) e $100 \mathrm{nM}$ (B) de PVA 30-70KDa. Potencial aplicado $100 \mathrm{mV}$. Nota-se um aumento na frequência dos bloqueios na corrente iônica com o aumento na concentração do PVA.

\section{CONCLUSÕES}

O nanoporo da a-Hemolisina interage e detecta o Polivinil álcool.

\section{REFERÊNCIAS}

AGUIAR, J. P. et al. Biossensoriamento estocástico via nanoporo proteico individual no desenvolvimento de ferramentas analíticas. Química Nova. v. 38, n. 6, p. 817-827, 2015.

AZEVEDO, M. M. Nanoesferas e a liberação controlada de fármacos. LQES - Laboratório de Química do Estado Sólido - Instituto de Química - UNICAMP, 2002.

BAAKEN et al. Nanopore-Based Single-Molecule Mass Spectrometry on a Lipid Membrane Microarray. ACS NANO, vol. 5, p. 8080-8088, 2015.

IKEDA S. et al. Polymer and Colloidal Models Describing StructureFunction Relationships. Annu. Rev. Food. Sci. Technol., 2012.

MANO, E. B. E MENDES, L. C. Introdução a polímeros. 2004.

MANRICH S. Processamento de termoplásticos, 2005.

MENDES et al. Estudo comparativo da reação inflamatória renal entre álcool de polivinil - flocular e álcool de polivinil + acetato de polivinil - esférico: estudo experimental. Rev. Col. Bras. Cir., vol.32, 2005.
MONTAL, M.; MUELLER, P. Formation of Bimolecular Membranes from Lipid Monolayers and A Study of Their Electrical Properties. Proceedings of the National Academy of Sciences of the United States of America, v. 69, p. 3561-3566. 1972.

ROBERTSON, J. W., C. G. RODRIGUES, V. M. STANFORD, K. A. RUBINSON, O. V. KRASILNIKOV, AND J. J. KASIANOWICZ. Singlemolecule mass spectrometry in solution using a solitary nanopore. Proc. Natl. Acad. Sci. USA. 104:8207-8211, 2007.

RODRIGUES, C. G.; MACHADO, D. C.; CHEVTCHENKO, S. F.; KRASILNIKOV, O.V. Mechanism of $\mathrm{KCl}$ Enhancement in Detection of Nonionic Polymers by Nanopore Sensors. Biophys. J., v. 95, p. 5186, 2008.

Apoio financeiro: CNPq, FACEPE, UFPE. 